\title{
Corrigendum: Energetics of Slope Flows: Linear and Weakly Nonlinear Solutions of the Extended Prandtl Model
}

\author{
Ivan Güttler ${ }^{1 *}$, Ivana Marinović ${ }^{2,3}$, Željko Večenaj $^{2}$ and Branko Grisogono ${ }^{2}$ \\ ${ }^{1}$ Meteorological and Hydrological Service of Croatia, Zagreb, Croatia, ${ }^{2}$ AMGI, Department of Geophysics, Faculty of \\ Science, University of Zagreb, Zagreb, Croatia, ${ }^{3}$ Department of Environmental Sciences, University of Virginia, Charlottesville, \\ $\checkmark A$, United States
}

Keywords: katabatic flow, anabatic flow, Prandtl model, nonlinear solution, total energy

\section{A corrigendum on}

Energetics of Slope Flows: Linear and Weakly Nonlinear Solutions of the Extended Prandtl Model

by Güttler, I., Marinović, I., Večenaj, Ž., and Grisogono, B. (2016). Front. Earth Sci. 4:72. doi: $10.3389 /$ feart.2016.00072

In the original article, there were mistakes in Figures 2, 4, $\mathbf{6}$ as published. The interaction term [last right-hand side term in Equation (3) of our published paper] was erroneously multiplied by the average heat conductivity constant. The corrected Figures $2 \mathrm{~A}-\mathrm{C}$, Figures $4 \mathrm{~A}-\mathrm{C}$, and Figure 6 appear below.

\section{OPEN ACCESS}

Edited and reviewed by:

Miguel A. C. Teixeira

University of Reading, United Kingdom

*Correspondence:

Ivan Güttler

ivan.guettler@cirus.dhz.hr

Specialty section:

This article was submitted to

Atmospheric Science,

a section of the journal

Frontiers in Earth Science

Received: 03 August 2017 Accepted: 22 September 2017

Published: 09 October 2017

Citation:

Güttler I, Marinović I, Večenaj Ž and Grisogono B (2017) Corrigendum: Energetics of Slope Flows: Linear and Weakly Nonlinear Solutions of the

Extended Prandtl Model.

Front. Earth Sci. 5:76.

doi: 10.3389/feart.2017.00076
Figure 2: Correction of the original Figure 2, panels A-C. Only panel C is updated.

Figure 4: Correction of the original Figure 4, panels A-C. Only panel C Is updated.

Figure 6: Correction of the original Figure 6. Panels from $\mathrm{C}$ to $\mathrm{H}$ are updated.

The same error that led to the correction of Figures 2, 4, $\mathbf{6}$ had an impact on the content of the paper. This error leads to five minor changes in several paragraphs:

(1) A correction has been made to Results, Katabatic flow, Nonlinear case, 1st paragraph. The following sentence (lines 11-12) is modified:

Its amplitude is comparable to the other two governing terms in the energy equation.

(2) A correction has been made to Results, Anabatic flow, Nonlinear case, 1st paragraph. The sentences spanning the last 9 lines of the paragraph have been modified as follows:

In contrast to katabatic flow, the TE diffusion DIF now departs from the dissipation DIS toward lower values (Figure 4C). Also, while in both katabatic and anabatic flow the amplitude of INT is comparable in magnitude to DIF and DIS, the sign of INT is now reversed, becoming negative in the case of anabatic flow.

(3) A correction has been made to Results, Energetics: Katabatic and Anabatic Flows, 5th paragraph. Here, several numerical estimates are now corrected and the following sentence (lines 9-11) is modified:

Also, INTmax varies from $\sim 0.01 \mathrm{~J} / \mathrm{kg} / \mathrm{s}$ to $\sim 0.07 \mathrm{~J} / \mathrm{kg} / \mathrm{s}$ in katabatic flow, while it is negative and varies from $\sim-0.07 \mathrm{~J} / \mathrm{kg} / \mathrm{s}$ to $\sim-0.01 \mathrm{~J} / \mathrm{kg} / \mathrm{s}$ in anabatic flow. 
(4) A correction has been made to Results, Energetics: Katabatic and Anabatic Flows, 6th paragraph. Again, several numerical estimates are now corrected and the following two sentences (line 6-10 and 13-16) are modified:

For nonlinear katabatic flow, and based on the specific selection of model parameters, maximum values of $\partial T E / \partial t$ range from $\sim 10^{-3} \mathrm{~J} / \mathrm{kg} / \mathrm{s}$ to $\sim 0.01 \mathrm{~J} / \mathrm{kg} / \mathrm{s}$ at heights ranging from $\sim 6$ to $\sim 10 \mathrm{~m}$ (Figures $6 \mathrm{C}, \mathrm{G}$ ).

For the nonlinear anabatic flow, maximum values of $\partial T E / \partial t$ range from $\sim 10^{-3} \mathrm{~J} / \mathrm{kg} / \mathrm{s}$ to $\sim 0.01 \mathrm{~J} / \mathrm{kg} / \mathrm{s}$ at heights ranging from $\sim 55$ to $\sim 82 \mathrm{~m}$ (Figures $6 \mathrm{D}, \mathbf{H}$ ).
(5) A correction has been made to Discussion, 4th paragraph. The following sentence from the 2 nd half of the paragraph (lines 27-31) is modified:

Also, imbalance among the energy terms in this nonlinear model may suggest that there is perhaps no real steady-state nonlinear slope flow; thus, excursions from pure steadiness could occur in nonlinear thermally driven flows.

The authors apologize for the computational error. Although the correction of this error had an impact in several places in the published paper, there are no changes in the scientific conclusions.
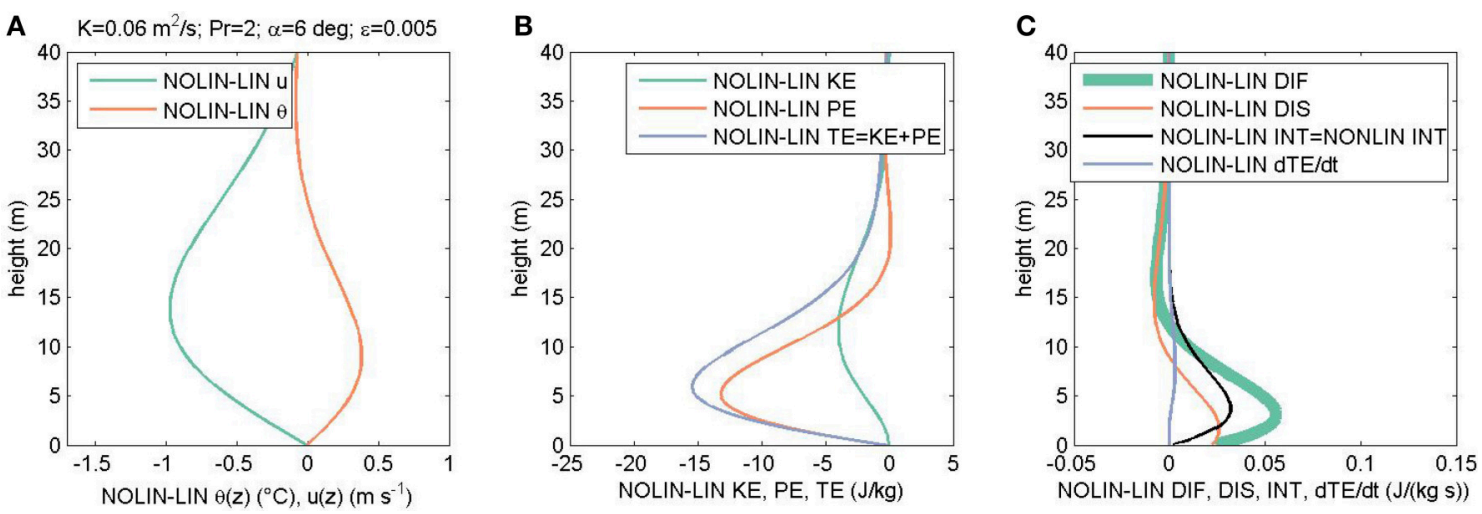

FIGURE 2 | (A-C) Differences between nonlinear and linear (Figure 1) solutions of the (extended) Prandtl model (cf. Grisogono et al., 2015). Panels (D-F) of the original Figure 2 are unchanged.
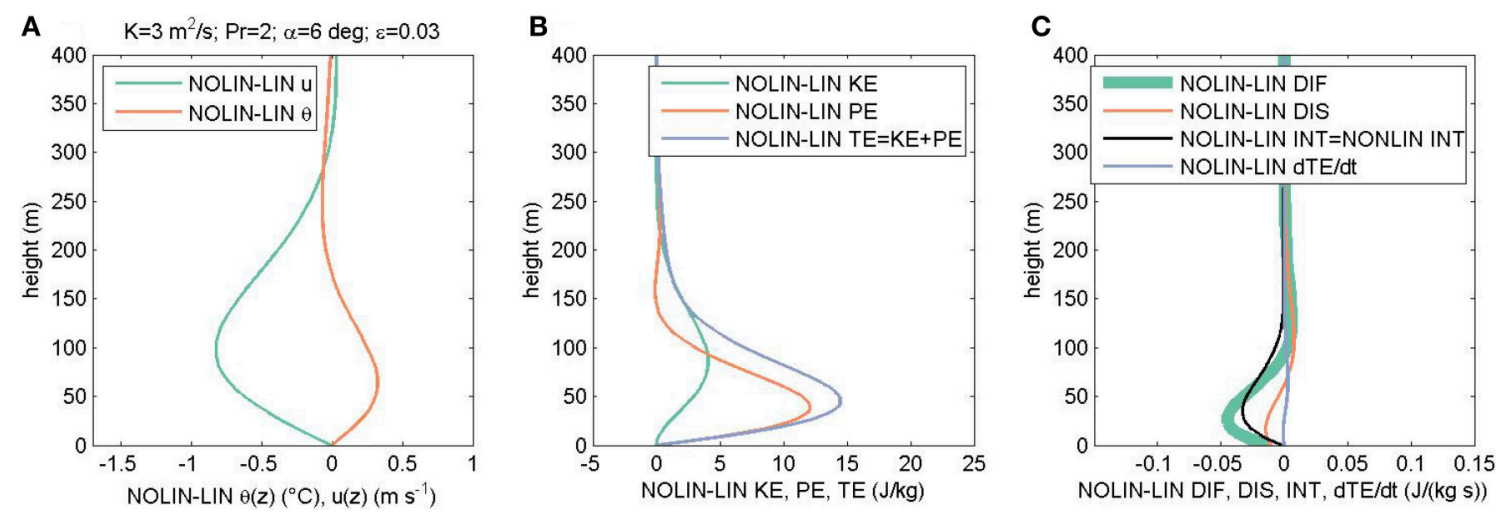

FIGURE 4 | Same as Figure 2 but for anabatic flow. 

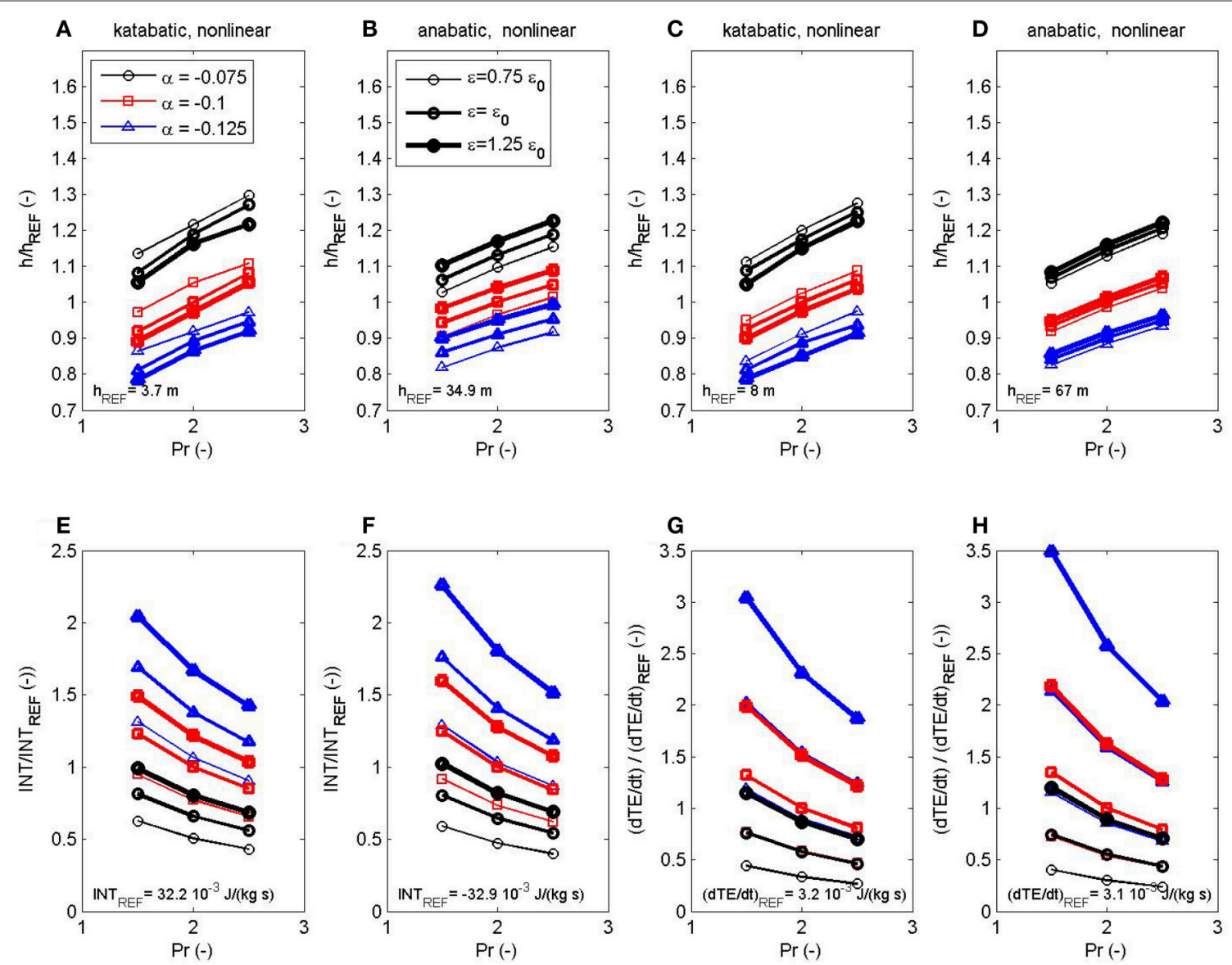

FIGURE 6 | The height of the maximum of the interaction term INT (A,B), the height of the maximum of the storage term $\partial T E / \partial t$ (C,D), the maximum INT value (E,F), and the maximum $\partial T E / \partial t$ value $\mathbf{( G , H ) ~ f o r ~ k a t a b a t i c ~}(\mathbf{A}, \mathbf{C}, \mathbf{E}, \mathbf{G})$ and anabatic (B,D,F,H) nonlinear cases. Selected measures are determined as functions of Prandtl number $\operatorname{Pr}$ (x axis), slope angle $\alpha$ (different color) and nonlinearity parameter $\varepsilon$ (different line thickness). Values in panels are relative to the corresponding $h_{R E F}$ (A-D), $I_{N T_{R E F}} \mathbf{( E , F )}$ and $\partial T E / \partial t_{R E F} \mathbf{( G , H )}$.

\section{REFERENCES}

Grisogono, B., Jurlina, T., Večenaj, Ž., and Güttler, I. (2015). Weakly nonlinear Prandtl model for simple slope flows. Q. J. R. Meteorol. Soc. 141, 883-892. doi: $10.1002 /$ qj.2406

Conflict of Interest Statement: The authors declare that the research was conducted in the absence of any commercial or financial relationships that could be construed as a potential conflict of interest.
Copyright (๑) 2017 Güttler, Marinović, Večenaj and Grisogono. This is an open-access article distributed under the terms of the Creative Commons Attribution License (CC $B Y$ ). The use, distribution or reproduction in other forums is permitted, provided the original author(s) or licensor are credited and that the original publication in this journal is cited, in accordance with accepted academic practice. No use, distribution or reproduction is permitted which does not comply with these terms. 